
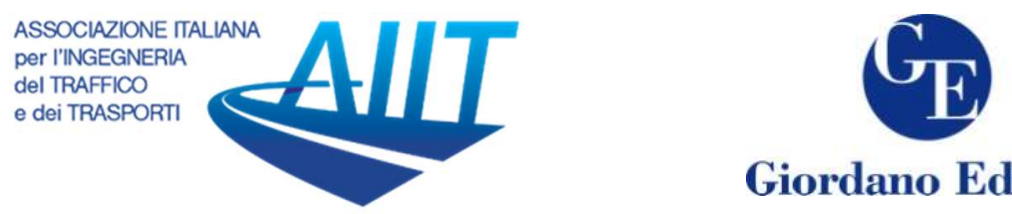

Giordano Editore

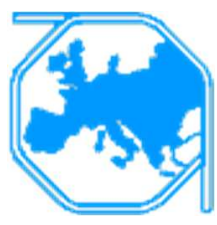

\title{
Assessment of Risk Associated with the Quiet Nature of Electric Vehicle: A Perception of EV Drivers and Pedestrians at Mumbai Metropolitan Region-India
}

\author{
Lalit N. Patil ${ }^{1 *}$, Hrishikesh P. Khairnar ${ }^{2}$ \\ ${ }^{l}$ Department of Mechanical Engineering, Veermata Jijabai Technological Institute, Mumbai, India \\ ${ }^{2}$ Department of Mechanical Engineering, Veermata Jijabai Technological Institute, Mumbai, India
}

\begin{abstract}
The key features of the electric vehicle (EV) from urban area emphasizes on clean air as well as quiet running nature to preserve atmospheric pollution conditions in the city, however, the new public health risk is arising due to calm running environment of electric vehicles. Since the electric vehicles run at low noise levels, pedestrians being troubled in road traffic accidents which tend to focus on the safety of the pedestrian. The aim of the present study is to analyze the perception of pedestrian's and driver's with the quiet nature of electric vehicles by evaluating the data obtained through a questionnaire survey and interviews conducted at the Mumbai Metropolitan Region (MMR), India. A total of 398 drivers of various driving experiences and 401 pedestrians from various locations of MMR had been responded to acquire technical data. A hypothesis is evaluated for public health risk associated with the quiet nature of electric vehicles from the driver's gender and age perspective. In addition, the ANOVA study was carried out to test the statistical significance of risk with respect to age, gender, vehicle usage, driving experience. The results illustrate that moderate risk is associated with the quiet nature of $\mathrm{EV}$ and more attention is required by road users as well as drivers, nevertheless gender $(\mathrm{P}=0.3321)$, profession $(\mathrm{P}=0.6537)$, driving experience $(\mathrm{P}=0.8888)$, vehicle use $(\mathrm{P}=0.3819)$ are not significant based on driver's perception ( $\mathrm{P}$ value greater than $0.05)$, whereas driver age group $(\mathrm{P}=0.0000)$ is accountable for perceived risk. Similarly, considering pedestrian's perception, gender ( $\mathrm{P}=0.7954)$, profession ( $\mathrm{P}=0.8188)$, distance walk $(\mathrm{P}=0.2313)$, location $(\mathrm{P}=0.3896)$ are not significant. The outcome of this study recommends the foremost need for the advanced control system in electric vehicles.
\end{abstract}

Keywords: Electric Vehicles, Pedestrian Safety, Road Traffic Accident, Risk Perception

\section{INTRODUCTION}

According to a recent study by WHO (2018), India is marked among the 20 most polluted cities in the world (World Health Organization, 2018). Major causes reported for continuous growth in pollution are automobile exhaust, inadequate control over emission levels from the vehicle, building construction activity, waste burning, traffic congestion, and many more (Bharadwaj et al., 2017; Guttikunda et al., 2014). One of the major sources of pollution is automobile vehicle exhaust gases. Electric vehicles (EVs) are the

* Corresponding author: Lalit N. Patil (Inpatil_p18@me.vjti.ac.in) 
most excellent alternative to improve the state of affairs by controlling local concentrations of pollutants in cities. The government of India has announced the National Electric Mobility Mission Plan (NEMMP) 2020 to enhance nationwide fuel security along with reasonable and eco-friendly transportation (Gulati, 2012). It will enable the Indian automotive business to attain global manufacturing. The key features of electric vehicle (EV) from urban area emphasizes on clean air as well as quiet running nature to preserve atmospheric pollution conditions in the city, however, the new public health risk is arising due to calm running environment of electric vehicles. Since the electric vehicles run at low noise levels, pedestrians being troubled in road traffic accidents (Lee et al., 2017; Ngueutsa and Kouabenan, 2017) which tend to focus on the safety aspects of the pedestrian.

The automotive sector has a dedication to constructing safer, inexpensive, and superior appearance vehicles. The continuous efforts from the research and development community have applied to the automobile industry to address the growing concerns not limited to global warming around the world but increase in vehicles safely and the shortfall of fossil fuels. The technical capabilities of electric vehicles to drive passenger cars are well known to automotive researchers however, only a few research articles are intended on the quiet running nature of the electric vehicles (Cocron and Krems, 2013; Hamzah et al., 2013; Pardo-Ferreira et al., 2020; Sandberg, 2012). The level of noise emission is negligible at moderate and low speed of electric vehicles which may cause an unintentional injury to the human body (pedestrian) which affects human health and may lead to a temporary injury or permanent disability (Cocron and Krems, 2013; PardoFerreira et al., 2020).

Definition of accident is broadly described as a surprising occurrence in a sequence of events, which generally produces unintentional injury, death, or damage of an object. Estimates by the World Health Organization (2018) propose that road crashes kill around 1.35 million of people per annum, and it is considered as $8^{\text {th }}$ leading cause of death for community of all ages (World Health Organization and issuing body, 2018). Pedestrian being troubled in road traffic accidents (RTA) is around $22 \%$ of all road traffic related deaths (Balasubramanian and Bhardwaj, 2018). India is ranked one in annual road fatalities and crossed to china furthermore it is expected to cross the mark of 250000 by 2025 (Singh, 2017). According to official statistics from government of India, around 147913 persons were killed in the year of 2017 whereas the 14500 accidental death cases were reported in 1970 which shows the rising trend of fatality in last 50 years (Handbook of basic Statistics of Maharashtra state, 2017). There is uneven distribution of past accident cases with respect to major cities in India(Mohan et al., 2016; Sikdar et al., 2017). It is also observed that the majority of fatal accident cases are from Uttar Pradesh, Tamil $\mathrm{Nadu}$, and Maharashtra states. Mumbai Metropolitan Region is the most populous metropolitan area in the world and situated in Maharashtra, India in which millions of pedestrians travel on road in a day. Since the Indian government announced the National Electric Mobility Mission Plan (NEMMP) 2020, electric vehicles are emergence on the road with great effectiveness (Gulati, 2012). Although the electric vehicles are environment friendly, their quiet running nature is the upcoming risk for pedestrian or road users. The scientific society predicted that the possibility of risk is associated with lower speeds, since at speed higher than $30 \mathrm{~km} / \mathrm{hr}$, tire noise on the road is greater and tends to mask the noise of the motor (Sandberg, 2012), the tire noise indicates the presence of vehicle, however, very limited literature is available on investigation of safety perception of silence electric vehicles (Balasubramanian and Bhardwaj, 2018; Cocron 
and Krems, 2013; Hamzah et al., 2013; Rolison et al., 2018; Singh, 2017). Therefore, the author's primary study intended to analyze the perception of pedestrian's and driver's with the quiet nature of electric vehicles at MMR.

The rest of this article is structured as follows: Section 2 introduces the region wise accidental data analysis to identify the most critical zone in India and need of present study. Data collection techniques and methodology adopted through questionnaires survey is discussed in section 3. Results based on the driver's studies and pedestrian's studies are presented in section 4 which elaborates the finding and interpretation of results related to the comprehensive study. Finally, Section 5 focuses on conclusive remarks with findings and future directions.

\section{ROAD ACCIDENTS}

Annually, more than 270000 pedestrians suffer from losing their lives across globe (World Health Organization, 2013). Many authors discussed their perception and remedies on road accident across globe such as crossing decisions of blind pedestrians (Sandberg, 2012; Wall Emerson et al., 2011), statistical analysis of accidents in a day (Goswami and Sonowal, 2009), comparative perceived risk analysis between cyclists and drivers (Chaurand and Delhomme, 2013). A recent study conducted by researchers in 2019 reveals that growth rate of road traffic accidents are exponential in case of India (Mahata et al., 2019). Few literatures emphasized on a preventive action plan required or need of advanced intelligent system to control the uncertain cases of incidences in India (Singh, 2017). Pedestrians are also merely responsible for accidents due to their confusing state of mind while crossing of road. Some bewilderment on the nature of oncoming traffic leads to delay in decision-making or result in them taking a wrong conclusion that can result in accident (Balasubramanian and Bhardwaj, 2018).

A. Trends of road traffic accidents in India

Road accidents around the world are a significant cause of unnatural death and injury. Figure 1 demonstrates the detailed accident scenario in India from year 2011 to 2015 wherein the rise in injury and persons killed are following up trend which is an alarming situation nowadays. Similarly, the linear pattern is observed considering cases of road accidents and person's injury as shown in figure 2 .

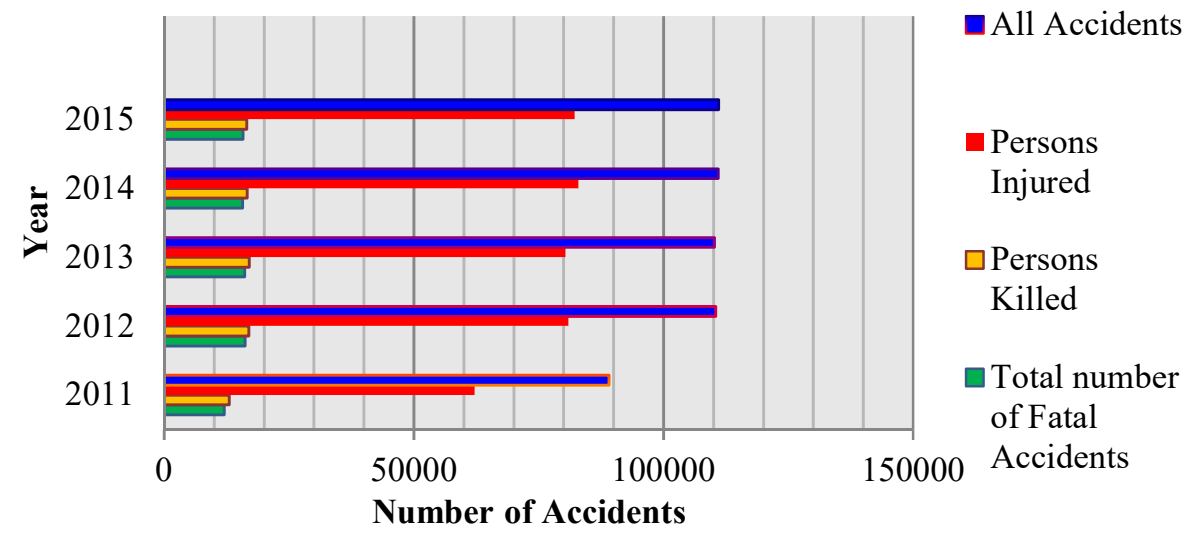

Figure 1: Number of persons injured, killed, fatal accidents in India, 2015.

(Source: Open Government Data (OGD) Platform India, available at https://data.gov.in/dataset-group-name/road-accidents) 


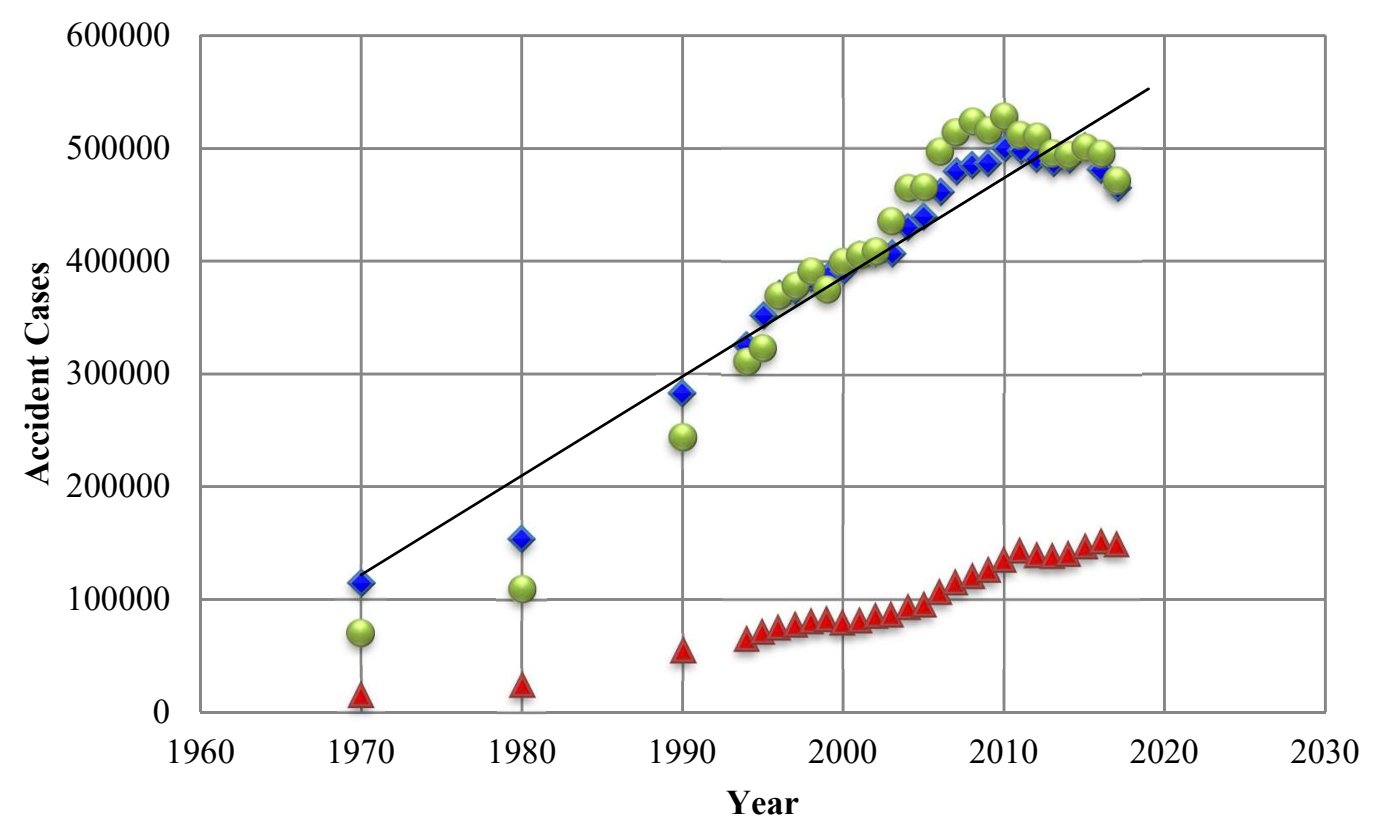

- Total Number of Road Accidents (in numbers)

$\Delta$ Total Number of Persons Killed (in numbers)

- Total Number of Persons Injured (in numbers)

— Lineare (Total Number of Road Accidents (in numbers))

Figure 2: Trends of road traffic accidents in India (Source: Open Government Data (OGD) Platform India)

\section{B. Electric vehicles and pedestrians}

Particularly in India, the public authority is attempting to acquaint electric vehicles on road to retain the atmospheric conditions (Gulati, 2012). It was proposed that hybrid and all-electric vehicles are so quiet in electric drive at low speed that they pose a safety threat to pedestrians and bicyclists (Sandberg, 2012). What's more, EVs are tricky to hear especially for pedestrians in the urban region (Pardo-Ferreira et al., 2020) as power unit noise (engine noise) is absolutely absent and only tyre noise remains (Sandberg, 2012). As the noise pollution is leading challenge for urban environment, the quiet EVs are difficult to identify by pedestrians especially in Indian cities.

Where it comes to accident/fatal situations, the previous available literatures are limited considering electric vehicle; nevertheless, we attempted to gather data from scientific articles in order to become acquainted with the real-world scenario. A recent research in Málaga, Spain, based on incidents that occurred while using electric cars, and it was discovered that nearly 62 percent of drivers interviewed reported unsafe situations or crashes (Pardo-Ferreira et al., 2020). Speed has been described as a primary risk factor in road traffic accidents, affecting both the likelihood of an accident and the seriousness of the injuries sustained as a result of collisions. In earlier studies, the speed limit of electric cars in the Netherlands was considered, and it was discovered that 72 percent of electric vehicle accidents occurred while the vehicle was running at a speed of $30-50 \mathrm{~km} / \mathrm{hr}$; consequently, the findings about accidental cases in regards to speed level are almost similar to those of traditional cars (Hoogeveen, 2010). Without advanced protection systems, there is a significant threat that new car architectures will become less safe in 
the event of an accident (Wismans et al., 2011). The recommendation from previous studies includes not only balance of active and passive safety but also crashworthiness future vehicles (Wismans et al. 2011). Electric vehicle crashes are seen as the upcoming challenge for reducing road traffic accidents (RTA). E-bikes, in particular, are being seen more on the road than electric cars. Researchers have been highly worried about the safety of e-bikes in recent years, owing to their growing prevalence and fatality incidence. The study related to accidents cases considering E-bikes was conducted in China. The study reveals that some factors like age, gender, education level, aggressive driving behaviour associated with E-bike riders and vehicles are statastically signifincant (Guo et al., 2017). Subsequently, Between 2014 and 2018, the different factors that lead to fatal injury in electric two-wheelers were comprehensively identified in Shandong Province, China. The study reveals that majority of electric two wheeler accidents took place at a speed range $50-60 \mathrm{~km} / \mathrm{hr}$ (Yang et al., 2020).

In view of this, it would be essential to evaluate the difficulty faced by electric vehicle drivers and road users. Although few articles emphasize the safety of e-bikes, the safety concerns for electric cars or electric autorickshaws are yet to evaluate cautiousely. What's more, pedestrians account for 22 percent of all traffic fatalities worldwide, and in certain nations, this number is as high as two-thirds. Millions of people are hospitalized in trafficrelated pedestrian accidents, with some being seriously disabled (World Health Organization, 2018). Considering the present need for study electric vehicle from multiple viewpoints, we took this task to learn about the perceptions of electric car drivers and pedestrians.

\section{MATERIALS AND METHODS}

India is one of the fastest growing countries in which about 31 per cent of population lives in the city areas. Mumbai is the most populated city in India and considered as a monetary and commercial centre of India. The Mumbai Metropolitan Region is an area composed of Mumbai along with its satellite towns from state of Maharashtra, India. Developing over a period of time, the population of MMR has also increased rapidly. Around millions of pedestrians are travelling in a day at various locations from city area and many of them suffered from minor or major incidence in traffic or on road while walking. Electric vehicles are also coming into sight with great popularity. Electric vehicle are Eco-friendly, however, the quiet running condition is becoming a new risk for pedestrian to judge the presence of vehicle; therefore, authors have conducted detailed technical questionnaires survey at the various locations from MMR.

\subsection{Data Collection}

This study was conducted in the cities of Mumbai Metropolitan Region during 2020. It consists of 9 Municipal Corporations (Mumbai, Thane, Kalyan-Dombivli, Navi Mumbai, Mira-Bhayandar, Bhiwandi-Nizampur, Ulhasnagar, Vasai-Virar, Panvel) covers total area of $4,354.50 \mathrm{~km}^{2}$. Sample size for the pedestrian survey was considered by using Slovin's formula. A total of 398 drivers of various driving experiences and 401 pedestrians from various location of MMR had been responded separately to acquire technical data based on random sampling. Respondents were advised about their response which will be purely used for research purposes and there have been no right or wrong answers for the questions so that their response would be processed anonymously. 
Table 1: Distribution of items administered to drivers

\begin{tabular}{|c|c|c|c|}
\hline Aspects Evaluated & Description & No. of Items & Degree of scale \\
\hline Low Noise Level & $\begin{array}{l}\text { Evaluation of the impact of } \\
\text { low noise level }\end{array}$ & 3 & \multirow{4}{*}{$\begin{array}{l}\text { Grade from } 1 \text { "very } \\
\text { strongly disagree" to } 6 \\
\text { "very strongly agree" }\end{array}$} \\
\hline Comfort & $\begin{array}{l}\text { To assess the effect of low } \\
\text { noise level on riding comfort }\end{array}$ & 2 & \\
\hline Time & $\begin{array}{l}\text { To examine the impact of low } \\
\text { noise on duration of trip }\end{array}$ & 2 & \\
\hline Safety of pedestrian & Evaluation of safety aspects & 3 & \\
\hline Severity & $\begin{array}{l}\text { To identify crushes, incidents } \\
\text { and assessment of the use of } \\
\text { electric vehicle }\end{array}$ & 10 & \multirow[t]{2}{*}{ Yes or No } \\
\hline Health & $\begin{array}{l}\text { To evaluate the health aspects } \\
\text { associated with use of EVs }\end{array}$ & 2 & \\
\hline & Total & 22 & \\
\hline
\end{tabular}

Table 2: Distribution of items administered to pedestrian based on driver's and pedestrian's perceptions.

\begin{tabular}{|c|c|c|c|}
\hline Aspects Evaluated & Description & No. of Items & Degree of scale \\
\hline Safety of pedestrian & Evaluation of safety aspects & 5 & \multirow{3}{*}{$\begin{array}{l}\text { Grade from } 1 \text { "very } \\
\text { strongly disagree" to } 6 \\
\text { "very strongly agree" }\end{array}$} \\
\hline Low Noise Level & $\begin{array}{l}\text { Evaluation of the impact of } \\
\text { low noise level }\end{array}$ & 4 & \\
\hline $\begin{array}{c}\text { Need for } \\
\text { advancement }\end{array}$ & $\begin{array}{l}\text { To identify the key attributes } \\
\text { for control }\end{array}$ & 4 & \\
\hline $\begin{array}{l}\text { Assessment of the } \\
\text { electric vehicle }\end{array}$ & $\begin{array}{l}\text { To identify crushes, incidents } \\
\text { and overall assessment }\end{array}$ & 8 & \multirow{2}{*}{ Yes or No } \\
\hline Health & $\begin{array}{l}\text { To evaluate the possible } \\
\text { impact on human health }\end{array}$ & 1 & \\
\hline & Total & 22 & \\
\hline
\end{tabular}

\subsection{Procedure}

Hereinafter, a structured electronic interview as well as on spot interview was conducted to acquire technical data through questioner's survey which was the primary step to reach towards research objective. The interview questions were planned based on the previous researcher's studies (Heights and Block, 2017; Ngueutsa and Kouabenan, 2017; Pardo-Ferreira et al., 2020). The data were collected by sending electronic invitation to various road users as well as face to face interview conducted in person with drivers and pedestrian separately. Their responses were cautiously examined for further analysis. The interview questions incorporated in three sections. The first section dedicated to collect demographic characteristics of drivers or pedestrians such as age, gender, profession, driving experience, location etc.

The second section of questions series contained 22 items based on driver's perception and pedestrian's perception as shown in Table 1 and Table 2 separately. Likert scale of 6 points is adopted for questionnaires rating followed from the previous research articles (Heights and Block, 2017; Pardo-Ferreira et al., 2020). Concise questionnaires composed of the question related to effect of low noise, comfort, time and safety. The objective of this section was to gather the precise information related to harmful effect, riding comfort and safety concerns.

The third section of question interview intended to cover the characteristics of risk, crushes and incidences. The participants were asked to answer the possibility of accidents, crushes and any uncertain cases of electric vehicles. 
Based on section stated above, hypotheses ( $\mathrm{H}_{0}$-Null hypothesis, $\mathrm{H}_{\mathrm{A}}$-Alternate hypothesis) were formulated to justify the critical factors affecting the incidence due to low quiet electric vehicles separately for drivers.

$\mathrm{H}_{0}$ : The level of risk for quiet EVs is not unlike according to whether the drivers were caught up in incidents with their gender or age.

$\mathrm{H}_{\mathrm{A}}$ : The level of risk for quiet EVs is different according to whether the drivers were caught up in incidents with their gender or age.

Since the research survey questions are exploratory, no specific hypotheses statement is stated in terms of risk severity.

\subsection{Participant}

The motives for selecting the Mumbai region for study as to majority of accidents were observed from Mumbai region. The rise in accident cases in various cities has been shown in figure 3. The social and demographic characteristics of pedestrians and drivers (participants) are shown separately in figure 4 and figure 5 respectively. Majority of surveyed participants from driver's survey were men with age range of 36 to 45 . Only $13 \%$ women reported their experiences as a driver's opinion whereas notable active participations were observed in case of pedestrian survey to express their view. Almost $50 \%$ of surveyed pedestrians fount from the private service profession who reported their views related to safety and risk associated with electric vehicles. It was also noticed that around $51 \%$ of people from the pedestrian surveys have more than $5 \mathrm{~km}$ daily walk.

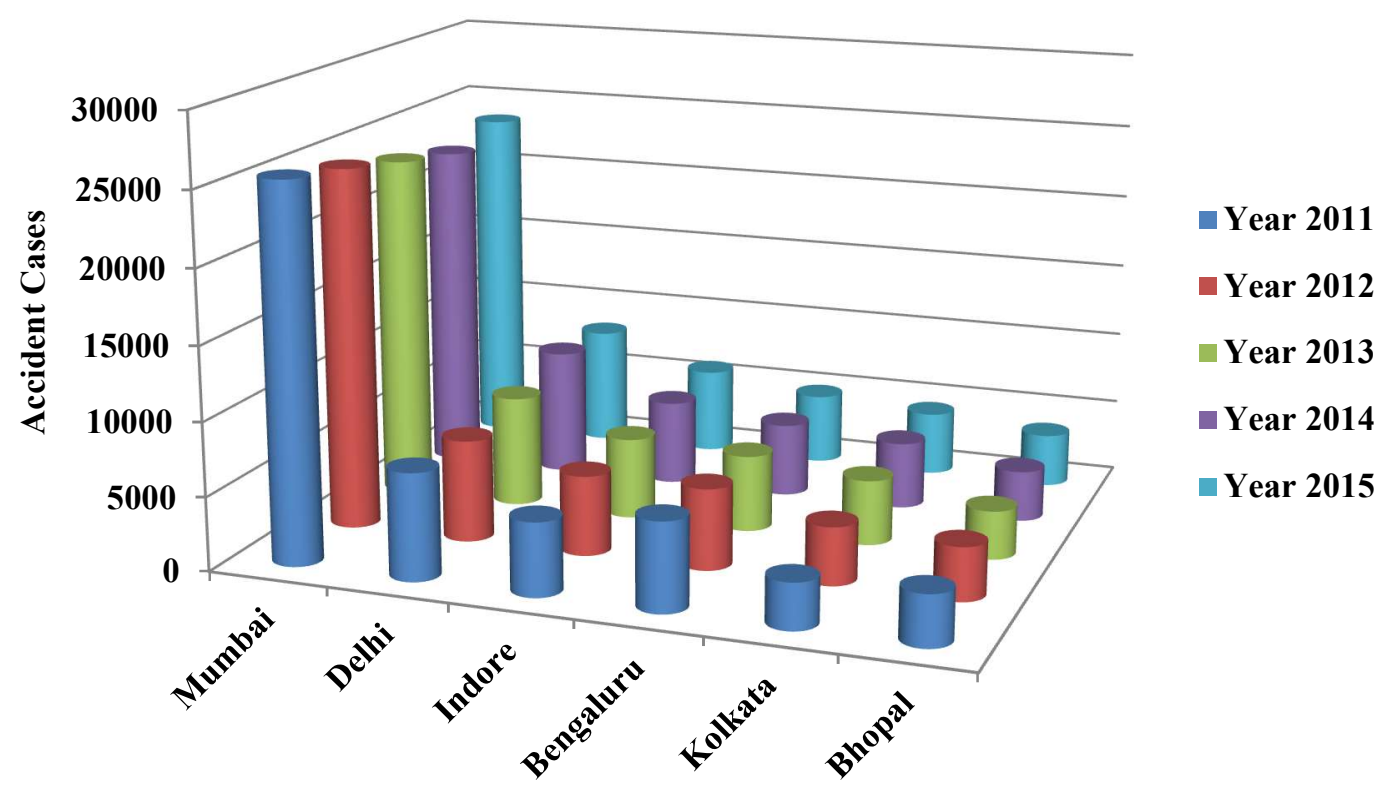

Major Cities from India

Figure 3: Year wise trend of accidents at major cities in India (Source: Open Government Data (OGD) Platform India) 

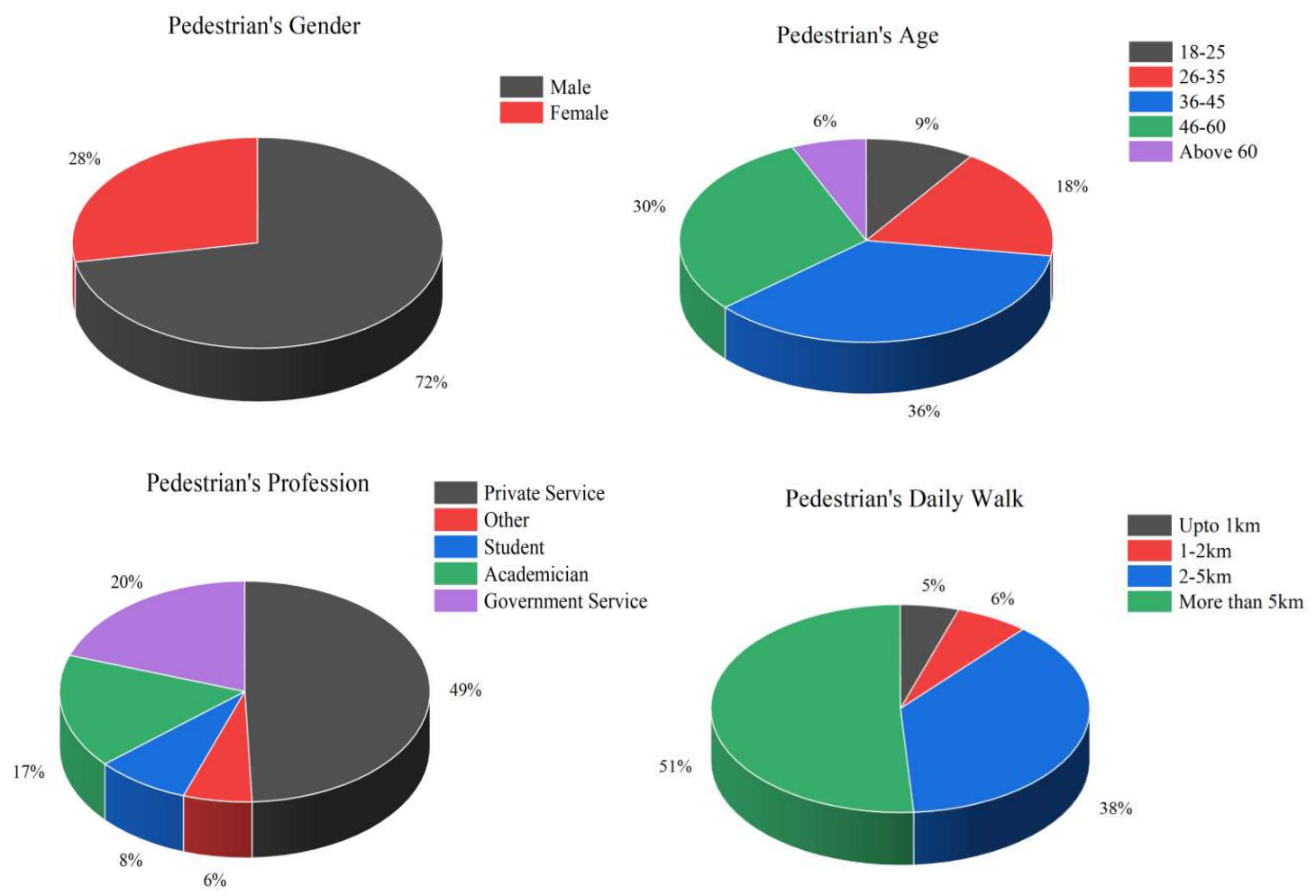

Figure 4: Key attribute of the surveyed participants-Pedestrians (Sample Size 401)
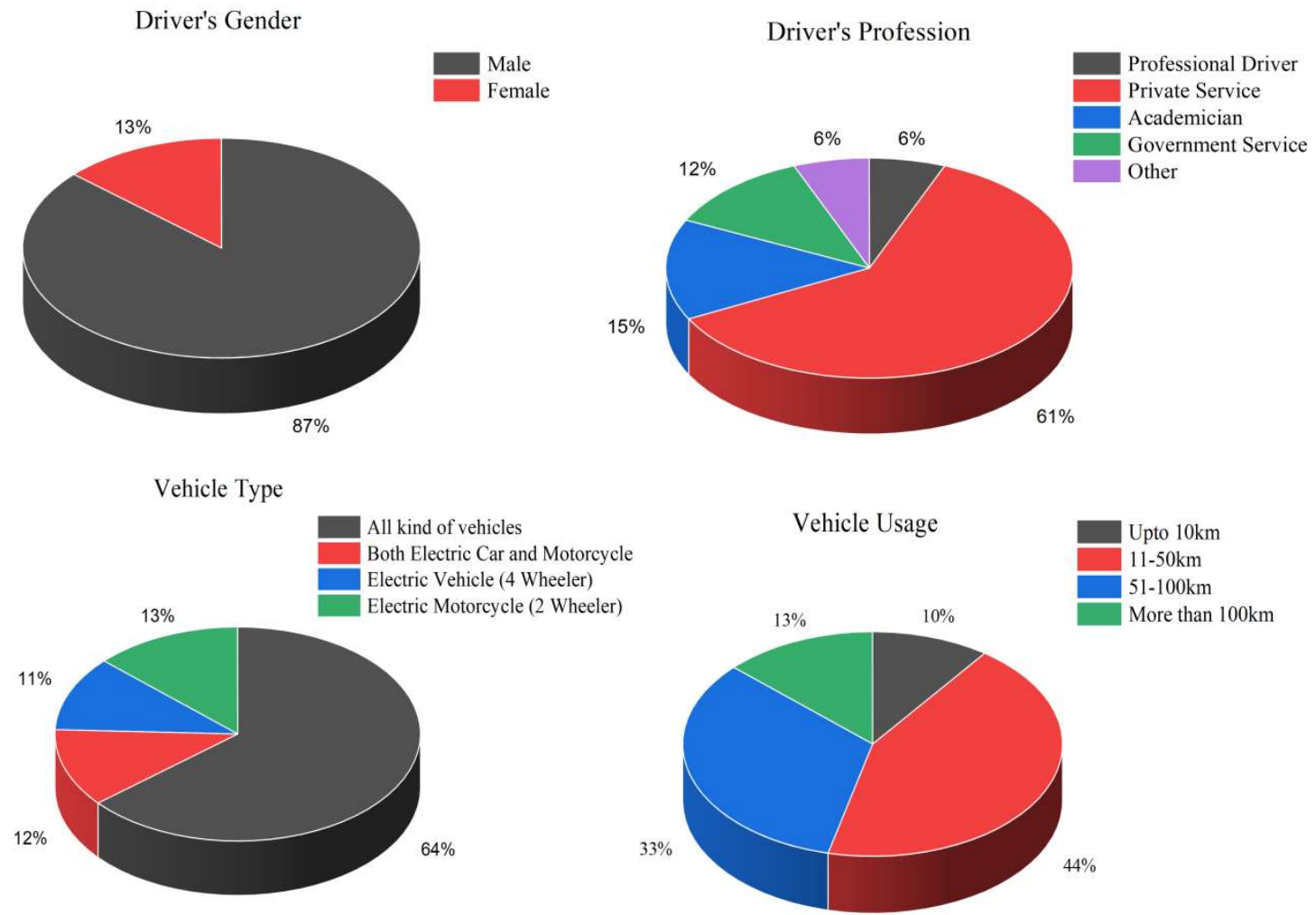

Figure 5: Key attribute of the surveyed participants-Drivers (Sample Size 398) 


\subsection{Analysis of Variance}

Analysis of variance (ANOVA) is a combination of statistical models used to evaluate the discrepancies between two or more independent variables and their associated measures (Farooq and Juhasz, 2020). The earlier study used ANOVA approach to measure effects of age, gender of predictor, vehicle speed (Hichim et al., 2020). The study of ANOVA includes valuable details on the model measures such as Degree of Freedom (DF), Mean Square (MS), F-Value, and P-Value. The total Degree of Freedom (DF) illustrates how much information is used by the model data. The value of the Mean Square (MS) represents how much the variation is explained by a term or model, assuming that all other components are in the model, irrespective of the sequence in which they are employed. Furthermore, the significance of F-value is to bear out the relationship of the factor with the response variable. In addition, the P-value is a probability which determines the evidence to reject the null. In conjunction with the P-value, the F statistic must be used when determining whether overall results are significant (Farooq and Juhasz, 2020).

Authors have followed the scientific approach to acquire the technical details related to Analysis of variance (ANOVA). The degree of freedom indicates the particulars that the data model has used. It can be achieved by deducting one number from total number of values in available independent variable source. The Mean of each group can be simply calculated from average of numbers. Moreover, to calculate the Mean Square (MS) value, the ratio of sum of square value to degree of freedom has been considered. In order to compute the F-Value, the variance of group means has been divided by means of the within group variable.

\section{RESULTS AND DISCUSSION}

\subsection{Driver's insight on the level of risk}

The majority of respondents reported that extreme attention is required while driving of electric vehicle at lower speed especially in city areas like Mumbai Metropolitan Region. The low noise level of electric vehicles would be foremost risk for pedestrians and thereby it requires cautions for driver for safe riding. Table 3 throws light on the various aspects evaluated such as low noise level, comfort, and travel time.

In spite of the requirement of extra attention, the drivers reported excellent comfort while driving electric vehicles. Mumbai and its allied area are always subjected to heavy traffic, therefore, it was also evaluated the aspects of safety and $45 \%$ of people are in line with the statement, "low noise of vehicle is the major root cause for heavy traffic at the urban region". The majority of drivers $(72 \%)$ agreed that the silent drive of an electric vehicle causes the chance of accidents. The comparative changes in driving behavior were reported by electric vehicle drivers as they required more attention while driving electric vehicles. Furthermore, Table 4 elaborates driver's perception related to crashes, and assessment of EVs. The reason for exploring the detiled results was to get the comprehensive information based on driver's views associated with their real time experience and incidences. The results shows that almost $66 \%$ of electric drivers experienced accidents at various locations. Most of people (84\%) agreed that electric vehicles are advantageous. If a smart safety control system is introduced for electric cars in the future ( $91 \%$ drivers agreed), it will boost popularity. 
Table 3: Driver's perception related to Low noise level, Comfort, Time and Safety of pedestrian

\begin{tabular}{|c|c|c|c|c|c|c|c|c|c|c|}
\hline $\begin{array}{l}\frac{\tilde{\Xi}}{\square} \\
\frac{\tilde{\pi}}{\pi}\end{array}$ & $\begin{array}{l}\text { Driver's } \\
\text { response } \\
\text { based on } \\
\text { following } \\
\text { questions }\end{array}$ & 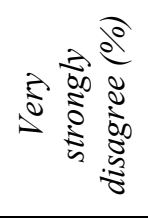 & 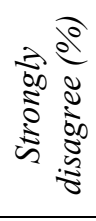 & 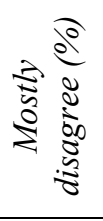 & 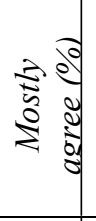 & 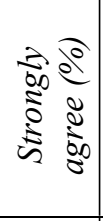 & 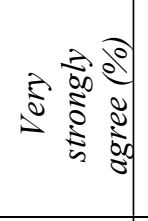 & 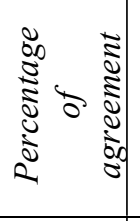 & $\begin{array}{l}\Xi \\
\Xi\end{array}$ & คิ \\
\hline \multirow{3}{*}{ 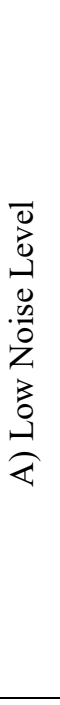 } & $\begin{array}{l}\text { 1) Electric } \\
\text { vehicle is } \\
\text { difficult for } \\
\text { pedestrians to } \\
\text { hear? }\end{array}$ & 6 & 2 & 7 & 25 & 19 & 42 & 86 & 4.76 & 1.39 \\
\hline & $\begin{array}{l}\text { 2) Low noise } \\
\text { of electric } \\
\text { vehicle is } \\
\text { potentially } \\
\text { risky? }\end{array}$ & 23 & 8 & 16 & 31 & 12 & 11 & 54 & 3.34 & 1.63 \\
\hline & $\begin{array}{l}\text { 3) A special } \\
\text { attention is } \\
\text { required while } \\
\text { driving an } \\
\text { electric vehicle } \\
\text { due to low } \\
\text { noise? }\end{array}$ & 27 & 8 & 23 & 22 & 10 & 9 & 41 & 3.06 & 1.61 \\
\hline \multirow{2}{*}{ 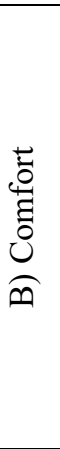 } & $\begin{array}{l}\text { 4) The riding } \\
\text { on electric } \\
\text { vehicle is } \\
\text { smooth and } \\
\text { comfortable. }\end{array}$ & 7 & 4 & 3 & 12 & 22 & 53 & 87 & 4.97 & 1.46 \\
\hline & $\begin{array}{l}\text { 5) Less stress } \\
\text { is observed } \\
\text { than normal IC } \\
\text { Engine vehicle } \\
\text { due to silent } \\
\text { drive. }\end{array}$ & 4 & 2 & 3 & 15 & 21 & 55 & 91 & 5.11 & 1.29 \\
\hline \multirow{2}{*}{$\begin{array}{l}\stackrel{0}{\Xi} \\
\stackrel{\Xi}{0}\end{array}$} & $\begin{array}{l}\text { 6) Extra time } \\
\text { is noticed due } \\
\text { to special } \\
\text { attention } \\
\text { required on } \\
\text { pedestrians. }\end{array}$ & 8 & 3 & 10 & 21 & 17 & 41 & 79 & 4.61 & 1.53 \\
\hline & $\begin{array}{l}\text { 7) Electric } \\
\text { vehicles are } \\
\text { time } \\
\text { consuming for } \\
\text { frequent start } \\
\text { and stop } \\
\text { conditions. }\end{array}$ & 33 & 8 & 25 & 17 & 9 & 9 & 34 & 2.85 & 1.64 \\
\hline 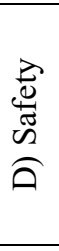 & $\begin{array}{l}\text { 8) The silent } \\
\text { drive of } \\
\text { electric vehicle } \\
\text { causes the } \\
\text { accidents } \\
\text { chances. }\end{array}$ & 13 & 6 & 10 & 27 & 15 & 30 & 72 & 4.17 & 1.66 \\
\hline
\end{tabular}




\begin{tabular}{|c|c|c|c|c|c|c|c|c|c|}
\hline $\begin{array}{l}\text { 9) Low noise } \\
\text { of vehicle is } \\
\text { the major root } \\
\text { for heavy } \\
\text { traffic in urban } \\
\text { region. }\end{array}$ & 18 & 8 & 28 & 29 & 8 & 8 & 45 & 3.25 & 1.45 \\
\hline $\begin{array}{l}\text { 10) The } \\
\text { electric vehicle } \\
\text { riding } \\
\text { movement is } \\
\text { quietness in } \\
\text { nature } \\
\text { however the } \\
\text { road users are } \\
\text { not in risk. }\end{array}$ & 16 & 10 & 23 & 25 & 7 & 20 & 52 & 3.57 & 1.65 \\
\hline
\end{tabular}

Table 4: Driver's perception related to crashes and assessment of EVs

\begin{tabular}{|c|c|c|c|}
\hline S. N. & Aspects & Yes $(\%)$ & No $(\%)$ \\
\hline 1) & Have you experienced accidents? & 66 & 34 \\
\hline 2) & Have you experienced any crashes? & 01 & 99 \\
\hline 3) & Have you experienced any incidence while parking of electric vehicle? & 17 & 83 \\
\hline 4) & $\begin{array}{l}\text { Have you experienced certain dangerous condition of electric vehicle while } \\
\text { travelling? (eg. Smell from battery/Battery blast) }\end{array}$ & 03 & 97 \\
\hline 5) & Do you feel that use of electric vehicle is reliable? & 92 & 08 \\
\hline 6) & Have you experienced crashes while overtaking of electric vehicles? & 23 & 77 \\
\hline 7) & Whether use of electric vehicle is advantageous? & 84 & 16 \\
\hline 8) & $\begin{array}{l}\text { Do you think intelligent control system is essential for electric vehicle due to } \\
\text { low noise while traveling on roads? }\end{array}$ & 91 & 09 \\
\hline 9) & Have you experienced any incidence of EV at traffic signal? & 24 & 76 \\
\hline 10) & Have you experienced the pollution effect due to electric vehicle? & 00 & 100 \\
\hline 11) & $\begin{array}{l}\text { Do you feel anxiety and fatigue after drive of electric vehicle due to extra } \\
\text { attention? }\end{array}$ & 25 & 75 \\
\hline 12) & Have you noticed any health issue due to use of electric vehicle? & 06 & 94 \\
\hline
\end{tabular}

\subsection{Pedestrian's insight on the level of risk}

The human health is strongly associated with safe travel of pedestrian. The accidental cases report from India shows a rising trend, as well as the majority of cases are related to pedestrian injury rather than driver, therefore, pedestrians need to be more precautious. The pedestrian respondents reveal a high severity of risk due to the noiseless operation of electric vehicles. Around $86 \%$ of pedestrians bring up the extra attention requires while walking on the road when there is the movement of electric vehicles on the road whereas $56 \%$ of people suggested that electric vehicles are more dangerous than IC engine vehicles as it has quiet running operations. In spite of that, roughly $50 \%$ of respondents reported being worried regarding the possibility of injury in any incidence. The detailed results of pedestrian's perception are shown in Table 5. 
Table 5: Pedestrian's perception related to Low noise level, Comfort, Time and Safety of pedestrian

\begin{tabular}{|c|c|c|c|c|c|c|c|c|c|c|}
\hline $\begin{array}{l}\frac{5}{0} \\
\frac{0}{\pi} \\
\frac{\pi}{4}\end{array}$ & $\begin{array}{l}\text { Pedestrian's } \\
\text { response based on } \\
\text { following } \\
\text { questions }\end{array}$ & 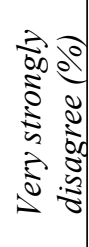 & 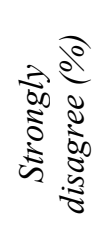 & 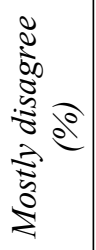 & 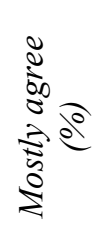 & 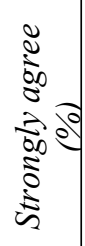 & 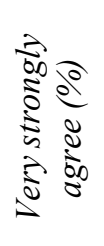 & 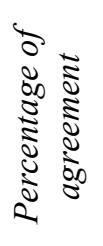 & $\underset{\Xi}{\Xi}$ & ڤิ \\
\hline \multirow{5}{*}{ 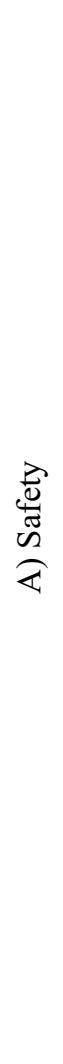 } & $\begin{array}{l}\text { 1) Extra attention } \\
\text { is required if an } \\
\text { electric vehicle } \\
\text { passing nearby to } \\
\text { you? }\end{array}$ & 6 & 2 & 6 & 25 & 19 & 42 & 86 & 4.74 & 1.41 \\
\hline & $\begin{array}{l}\text { 2) The silent drive } \\
\text { of electric vehicle } \\
\text { causes the } \\
\text { accidents chances? }\end{array}$ & 12 & 12 & 15 & 31 & 17 & 11 & 60 & 3.62 & 1.5 \\
\hline & $\begin{array}{l}\text { 3) I think, low } \\
\text { noise of vehicle is } \\
\text { the major root for } \\
\text { heavy traffic in } \\
\text { urban region. }\end{array}$ & 21 & 12 & 16 & 30 & 7 & 14 & 52 & 3.34 & 1.65 \\
\hline & $\begin{array}{l}\text { 4) The electric } \\
\text { vehicle riding } \\
\text { movement is } \\
\text { quietness in nature } \\
\text { however the road } \\
\text { users are not in } \\
\text { risk. }\end{array}$ & 8 & 12 & 13 & 30 & 14 & 23 & 67 & 3.99 & 1.55 \\
\hline & $\begin{array}{l}\text { 5) I observed the } \\
\text { sever accident } \\
\text { cases due to } \\
\text { Electric vehicles. }\end{array}$ & 12 & 6 & 9 & 27 & 15 & 30 & 72 & 4.17 & 1.67 \\
\hline \multirow{4}{*}{ 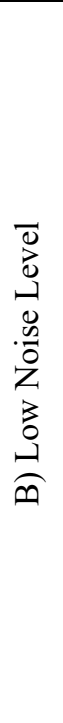 } & $\begin{array}{l}\text { 6) Electric vehicle } \\
\text { is difficult for } \\
\text { pedestrians to } \\
\text { hear? }\end{array}$ & 6 & 5 & 9 & 21 & 19 & 40 & 81 & 4.64 & 1.48 \\
\hline & $\begin{array}{l}\text { 7) Low noise of } \\
\text { electric vehicle is } \\
\text { potentially risky? }\end{array}$ & 9 & 11 & 16 & 29 & 11 & 23 & 63 & 3.92 & 1.57 \\
\hline & $\begin{array}{l}\text { 8) A special care } \\
\text { should require } \\
\text { while walking on } \\
\text { road since quiet } \\
\text { nature of electric } \\
\text { vehicle. }\end{array}$ & 8 & 7 & 10 & 24 & 18 & 32 & 74 & 4.33 & 1.58 \\
\hline & $\begin{array}{l}\text { 9) A quiet nature } \\
\text { of EVs is helpful } \\
\text { for maintaining } \\
\text { the noise pollution } \\
\text { level. }\end{array}$ & 5 & 8 & 8 & 17 & 15 & 47 & 78 & 4.68 & 1.56 \\
\hline
\end{tabular}




\begin{tabular}{|c|c|c|c|c|c|c|c|c|c|c|}
\hline \multirow{4}{*}{$\begin{array}{l}\Xi_{0} \\
\stackrel{\Xi}{0} \\
0\end{array}$} & $\begin{array}{l}\text { 10) Development } \\
\text { of key elements in } \\
\text { respect of } \\
\text { advanced vehicle } \\
\text { control system } \\
\text { will be helpful to } \\
\text { resolve accident } \\
\text { related cases and } \\
\text { improves safety to } \\
\text { pedestrians. }\end{array}$ & 15 & 10 & 12 & 24 & 14 & 25 & 63 & 3.87 & 1.73 \\
\hline & $\begin{array}{l}\text { 11) Electric } \\
\text { vehicles are more } \\
\text { dangerous than IC } \\
\text { engine vehicles } \\
\text { with respect to } \\
\text { accidental cases? }\end{array}$ & 15 & 12 & 16 & 29 & 15 & 12 & 56 & 3.53 & 1.56 \\
\hline & $\begin{array}{l}\text { 12) Electric } \\
\text { vehicle require } \\
\text { anonymous sound } \\
\text { while running on } \\
\text { road? }\end{array}$ & 9 & 5 & 11 & 29 & 18 & 26 & 74 & 4.21 & 1.53 \\
\hline & $\begin{array}{l}\text { 13) Electric } \\
\text { vehicles are } \\
\text { advantageous if } \\
\text { advancement with } \\
\text { respect of } \\
\text { pedestrian safety? }\end{array}$ & 9 & 10 & 10 & 27 & 15 & 29 & 72 & 4.17 & 1.6 \\
\hline \multicolumn{11}{|c|}{$\begin{array}{l}\text { Table 6: Pedestrian's perception related to crashes, health aspects and assessment of } \\
\qquad \text { EVs }\end{array}$} \\
\hline$S . N$. & \multicolumn{7}{|c|}{ Aspects } & & es (\%) & No $(\%)$ \\
\hline 1) & \multicolumn{8}{|c|}{ Have you experienced accidents? (Self Accident) } & 33 & 67 \\
\hline 2) & \multicolumn{8}{|c|}{$\begin{array}{l}\text { Have you experienced death of passenger/pedestrian in major accidents } \\
\text { in case of electric vehicle? }\end{array}$} & 00 & 100 \\
\hline 3) & \multicolumn{8}{|c|}{$\begin{array}{l}\text { Have you experienced certain dangerous condition of electric vehicle } \\
\text { while travelling? (eg.vehicle blast/Battery blast) }\end{array}$} & 00 & 100 \\
\hline 4) & \multicolumn{8}{|c|}{ Do you feel that use of electric vehicle is reliable? } & 84 & 16 \\
\hline 5) & \multicolumn{8}{|c|}{$\begin{array}{l}\text { Whether use of electric vehicle is advantageous over regular IC engine } \\
\text { vehicle? }\end{array}$} & 79 & 21 \\
\hline 6) & \multicolumn{8}{|c|}{$\begin{array}{l}\text { Do you think intelligent control system is essential for electric vehicle } \\
\text { due to low noise while traveling on roads? }\end{array}$} & 96 & 04 \\
\hline 7) & \multicolumn{8}{|c|}{$\begin{array}{l}\text { Have you observed any accident of pedestrian while crossing at traffic } \\
\text { signal due to Electric vehicle? }\end{array}$} & 17 & 83 \\
\hline 8) & \multicolumn{8}{|c|}{ Have you experienced the pollution effect due to electric vehicle? } & 00 & 100 \\
\hline 9) & \multicolumn{8}{|c|}{$\begin{array}{l}\text { Have you noticed any health issue due to road users because of electric } \\
\text { vehicle? }\end{array}$} & 05 & 95 \\
\hline
\end{tabular}


The pedestrian perception analysis discloses that the reason for heavy traffic in the city is due to the low noise level of electric vehicles. Although $86 \%$ of surveyed pedestrian brings to notice regarding the difficulty in identifying the presence of the electric vehicle when it passes nearby to them, the majority of people appreciated the use of an electric vehicle as it is controlling the state of noise pollution. Table 6 highlights pedestrian's perception related to crashes, health aspects and assessment of EVs.

\subsection{Analysis of the hypotheses developed}

A non-parametric approach is used to justify the state of perceived risk. The group participants with age higher than 35 years old are considered as Group A, whereas the participant having age less than 35 years considered with Group B. Around 66\% of participants were from Group A and remainders of Group B. A Mann-Whitney test showed that perceived risk did not differ with the age group of drivers $(P=0.54186, Z=$ $-0.60578, \mathrm{U}=17030.5)$.

Similarly, In line with null hypothesis statement, the result shows that there is no significant difference between genders of driver in terms of risk $(\mathrm{P}=0.321, \mathrm{Z}=-0.991$, $\mathrm{U}=8388.50)$ as the $\mathrm{P}$ value is greater than 0.05 .

\subsection{Analysis of variance results}

The Analysis of Variance (ANOVA) was performed to determine the influence of gender of drivers, age group, vehicle usage, profession, driving experience, and vehicle type as shown in Table 7. The age group of drivers shows statically significant as its $\mathrm{F}$ value is greater than $\mathrm{F}_{\text {crit }}$, whereas, remaining factors are observed statically nonsignificant as the F value is less than Fcrit. Similarly, ANOVA approach was also adopted to evaluate the significance of factors like gender, age, distance, profession, location, and time from pedestrian perspective. The results shows that all the items are non significant as its $\mathrm{F}$ value is less than $\mathrm{F}$ crit as shown in Table 8.

Table 7: ANOVA analysis results based on driver's risk perception

\begin{tabular}{lcccccc}
\hline \multicolumn{1}{c}{ Criteria } & $S S$ & $d f$ & $M S$ & $F$ & $P$-value & $F$ crit \\
\hline Gender & 3.146196 & 1 & 3.146197 & 1.188759 & 0.276243 & 3.865048 \\
Age group & 142.7946 & 4 & 35.69866 & 17.40334 & 0.000000 & 2.394649 \\
Vehicle usage & 8.131125 & 3 & 2.710375 & 1.023786 & 0.381965 & 2.627556 \\
Profession & 6.515268 & 4 & 1.628817 & 0.612740 & 0.653691 & 2.394648 \\
Driving Experience & 4.532616 & 5 & 0.906523 & 0.339510 & 0.888854 & 2.237012 \\
Vehicle Type & 0.389051 & 3 & 0.129684 & 0.048624 & 0.985792 & 2.627556
\end{tabular}

Table 8: ANOVA analysis results based on pedestrian's risk perception

\begin{tabular}{lcccccc}
\hline \multicolumn{1}{c}{ Criteria } & $S S$ & $d f$ & $M S$ & $F$ & P-value & F crit \\
\hline Gender & 0.1658060 & 1 & 0.165806 & 0.067339 & 0.795385 & 3.864870 \\
Age group & 4.2324100 & 4 & 1.058102 & 0.428272 & 0.788227 & 2.394476 \\
Distance of walk & 10.559280 & 3 & 3.519761 & 1.437533 & 0.231347 & 2.627384 \\
Profession & 3.8144080 & 4 & 0.953602 & 0.385810 & 0.818798 & 2.394476 \\
Location & 10.151350 & 4 & 2.537837 & 1.033453 & 0.389649 & 2.394476 \\
Time & 18.062083 & 3 & 6.020694 & 2.478085 & 0.060865 & 2.627384
\end{tabular}




\subsection{Discussion}

Individual experience is an influential, nevertheless complex determinant of self defensive behaviors. One would possibly foresee to that someone who has been caught up in an accident would consequently demonstrate more concern about risk and behave additional safely (Weinstein, 1989). In quest of this, the analysis shows the requirement of preventive measures to increase the safety ability for road users in the case of electric vehicles. Authors numerous findings are likely to stick with previous findings from researchers (Chaurand and Delhomme, 2013; Illahi and Tabbussum, 2020), however some additional observations are found in drivers and pedestrian perception.

The detailed ANOVA study was conducted considering the group of participants (Illahi and Tabbussum, 2020; Pardo-Ferreira et al., 2020). Firstly, the detailed analysis of driver's perception shows that there is no significant difference between the gender of drivers $(\mathrm{F}=1.188759<\mathrm{Fcrit})$ which was targeted with 87 percent of males and the remainders were females. Furthermore, age group of driver was considered. Since the Pvalue is equal zero and additionally measured $F$ value $(F=17.40334)$ is higher than Fcrit, it attracts the attention of researchers. Age group is the significant factor from driver's investigation point of view. Authors considered five groups (18-25, 26-35, 36-45, 46-60, above 60) for the study in which most of participants were found from 36-45 age group $(36 \%)$. Less awareness of people, heavy traffic distraction, low concentration with age could be the possible reason for the risk associated with age group. The daily use of vehicle and its effect was studied considering four groups (travel upto $10 \mathrm{~km}, 11-50 \mathrm{~km}$, $51-100 \mathrm{~km}$, and more than $100 \mathrm{~km}$ ). The analysis shows that there is no significant difference considering distance travelled by drivers in a day basis $(\mathrm{F}=1.023786<\mathrm{Fcrit})$. Professional drivers are enough expertise in driving and they travel much more distance than private car drivers, therefore we extend our study to examine their effect. The investigation stick on the findings that the risk is not significant based on profession $(\mathrm{F}=0.61274<\mathrm{Fcrit})$ in view of five group of participants. Besides, the driving experience and age group is most considerable factor to drive safely (Farooq and Juhasz, 2020; Hichim et al., 2020). The results from previous study reveals that young drivers (18-21) with less than one year of driving experience are much more likely to engage risk (Farooq and Juhasz, 2020) which are nearly similar to our findings related to age group, however, there is no significant differences in risk between the various driving experience group of people $\mathrm{F}=0.33951<$ Fcrit $)$. Although electric vehicles are noiseless and smooth for drive, the effect of risk was also examined bearing in mind type of vehicle (IC engine/Electric Vehicle). The observe F value (0.048624) is less than F critical value; it gives the evidence for non statistical significance.

Moreover, the further study of ANOVA based on pedestrian shows that there is no significant difference between genders of pedestrian $(\mathrm{F}=0.067339<\mathrm{Fcrit})$. The millions of people used to walk daily in MMR having various age, therby we consider the age group for further evaluation. The reults shows that $F$ value $(0.428272)$ is smaller than Fcrit means there is no significant difference of risk between the various age group of pedestrian $(18-25,26-35,36-45,46-60$, above 60$)$. It was revealed that around $50 \%$ of people are walking on the road for more than $5 \mathrm{~km}$ in a day. Considering the walkabilty as a factor, authors analyze the perception of pedestrian and revealed that the perceived risk is different irrespective of distance walk by pedestrain $(\mathrm{F}=1.437533<\mathrm{Fcrit})$. Similarly, the variety of people had daily walk at various location, therefore, the next factor for analysis was chosen as location (Urban/ City, Rural, Urban and rural area, High way / Free way, Urban Freeway/High way). The ANOVA results reveal that there is no 
significant difference between the location $(\mathrm{F}=1.033453<\mathrm{Fcrit})$. Finally, the profession of pedestrians and time span at which they used to walk were examined cautiously. The perceived risk is not associated with the profession of pedestrian $(\mathrm{F}=0.38581)$ as well as time span $(\mathrm{F}=2.478085)$ as the variety of people walk daily on road at various time of a day, however, some previous study elaborates that there is significant risk associated with time span (6am-6pm) of walk (Goswami and Sonowal, 2009). The reason for this could be the researchers consideration about time span $(6 \mathrm{am}-6 \mathrm{pm})$ at which most of people are active and mobile.

The interesting portion of the current research focuses on driver's age criteria. A MannWhitney test showed that perceived risk did not differ with the age group of drivers $(\mathrm{P}=$ $0.54186, Z=-0.60578, U=17030.5)$, whereas the second part of the ANOVA analysis elaborates the possibility of risk with respect to age group. Since the P-value is equal zero and additionally measured $\mathrm{F}$ value $(\mathrm{F}=17.40334)$ is higher than Fcrit, age group is the significant factor from driver's investigation point of view. The selection of group limit for two various analyses could be possible reason for differ in results.

Finally, the possible risk associated was evaluated cautiously for Mumbai Metropolitan Region from two various perspectives on the basis of drivers and pedestrians opinion. The outcome has realistic implications intended for the prevention of traffic accidents considering future era of electric vehicles. Although the presence of electric vehicles (Gulati, 2012) on the market road compete for a distinctive breakthrough in the reduction of urban residence noise to maintain a fine state of atmospheric noise pollution, still most of the respondents responded that there would be a high risk of an electric vehicle for safety of pedestrians. When the electric vehicle is traveling at a speed of less than 30 $\mathrm{km} / \mathrm{h}$, low noise (within specific one-third octave band ranges between 160 and $5000 \mathrm{~Hz}$ ) should be produced to detect the presence of an electric vehicle (Dalrymple, 2013) but this could not justify the state of risk. The most of drivers and pedestrians respondent responded positively (91\% drivers and $96 \%$ pedestrian) with the question "Do you think an intelligent control system is essential for electric vehicles due to low noise while traveling on roads?" which leads to raise an extensive research on advanced vehicle control system for enhancing the safety for pedestrians.

\section{CONCLUSION}

The study evaluated the perception of drivers and pedestrians based on their age group, driving experience, gender, profession, location, distance of walk in context of quiet nature of electric vehicle. The study reveals that drivers are more worried for safe drive irrespective of their age group particularly in heavy traffic. The pedestrian express their views for the people who are the persons with disabilities (Divyangjan) have lot of possibility of risk especially for blind pedestrian. EVs are trickier to hear for people particularly at lower speed in the city region. The outcome of the ANOVA analysis is appended in brief as follows:

- The perceived risk is significantly different with the age group of drivers.

- The factors such as gender of drivers, driving experience, profession, vehicle usage in a day are observed statistically non-significant.

- There is no statistical difference of risk between traditional IC engine vehicles and electric vehicles for road users in view of driver's perception.

- The pedestrian participant's gender, age group, profession, distance of walk, location, and time are not significantly associated with risk due to low noise.

- In traffic situation, the presence of electric vehicle is difficult to predict for road users. 
The analysis shows that drivers are more cautious in case of electric vehicles particularly moving in traffic which can be clarified due to uncontrolled traffic, low noise level of EV and ignorance of traffic rule by pedestrian. While, many pedestrian with observed groups are found to be having more afraid, especially in the traffic zone due to low noise level of EV. However, strategic control of electric vehicles should be incorporated for better safety. An enhanced braking technique and advanced neural network application for any EV control may allow the electric vehicle to become more reliable and popular in society, thereby, it requires more research on advanced EV control strategy.

\section{References}

Balasubramanian, V., Bhardwaj, R. (2018) "Pedestrians' perception and response towards vehicles during road-crossing at nighttime" Accident Analysis \& Prevention, 110, pp. 128-135. https://doi.org/10.1016/j.aap.2017.10.025.

Bharadwaj, S., Ballare, S., Rohit, Chandel, M.K. (2017) "Impact of congestion on greenhouse gas emissions for road transport in Mumbai metropolitan region" Transportation Research Procedia, 25, pp. 3538-3551. https://doi.org/10.1016/ j.trpro.2017.05.282.

Chaurand, N., Delhomme, P. (2013) "Cyclists and drivers in road interactions: A comparison of perceived crash risk" Accident Analysis \& Prevention, 50, pp. 11761184. https://doi.org/10.1016/j.aap.2012.09.005.

Cocron, P., Krems, J. F. (2013) "Driver perceptions of the safety implications of quiet electric vehicles" Accident Analysis \& Prevention, 58, pp. 122-131. https://doi.org/10.1016/j.aap.2013.04.028.

Dalrymple, G. (2013) "Minimum sound requirements for hybrid and electric vehicles: Draft environmental assessment" NHTSA, Washington, DC, Document number: NHTSA-2011-0100.

Farooq, D., Juhasz, J. (2020) "Statistical Evaluation of Risky Driver Behavior Factors that Influence Road Safety based on Drivers Age and Driving Experience in Budapest and Islamabad", 80, European Transport, Paper No 2.

Goswami, A., Sonowal, R. (2009) "A Statistical Analysis Of Road Traffic Accidents In Dibrugarh City, Assam, India" 14, Interstat, pp. 1-14.

Gulati, V. (2012) "National electric mobility mission plan 2020" Department of Heavy Industry, Ministry of Heavy Industries \& Public Enterprises, Government of India.

Guo, Y., Zhou, J., Wu, Y., \& Chen, J. (2017). Evaluation of factors affecting e-bike involved crash and e-bike license plate use in China using a bivariate probit model. Journal of advanced transportation, 2017.

Guttikunda, S.K., Goel, R., Pant, P. (2014) "Nature of air pollution, emission sources, and management in the Indian cities" Atmospheric Environment, 95, pp. 501-510. https://doi.org/10.1016/j.atmosenv.2014.07.006.

Hamzah, A., Solah, M.S., Ariffin, A.H. (2013) "Electric motorcycle risks on roads: An overview" Proceedings from the Southeast Asia Safer Mobility Symposium, Melaka, Malaysia.

Heights, W., Block, A. (2017) "Pedestrian Survey: Identifying pedestrian knowledge, perceptions of and attitudes on road safety in Baku", The National Automobile Club of Azerbaijan. 
Hichim, M.F., Khusheef, A.S., Hasan, S. (2020) "The Effects of Driver Age and Gender on Vehicle Stopping Distance Under Different Speeds", 80, European Transport, Paper No 1.

Hoogeveen, L. V. J., (2010) "Road traffic safety of silent electric vehicles" Onderzoeksthesis, Universiteit Utrecht.

Illahi, U., Tabbussum, R. (2020) "Identification of High-Risk Road Traffic Crash Zones for Spatial Allocation and Distribution of Proximate Health-Care Facilities: An Application of GIS Tools" International Journal on Emerging Technologies 11(4), pp. 17-22.

Mahata, D., Narzary, P.K., Govil, D. (2019) "Spatio-temporal analysis of road traffic accidents in Indian large cities" Clinical Epidemiology and Global Health, 7, pp. 586591. https://doi.org/10.1016/j.cegh.2019.01.005.

Mohan, D., Tiwari, G., Mukherjee, S. (2016) "Urban traffic safety assessment: A case study of six Indian cities", IATSS Research 39, pp. 95-101. https://doi.org/ 10.1016/j.iatssr.2016.02.001

Ngueutsa, R., Kouabenan, D. R. (2017) "Accident history, risk perception and traffic safe behaviour. Ergonomics", 60, pp. 1273-1282. https://doi.org/10.1080/00140 139.2016.1259508

Pardo-Ferreira, M. del C., Rubio-Romero, J. C., Galindo-Reyes, F.C., Lopez-Arquillos, A. (2020) "Work-related road safety: The impact of the low noise levels produced by electric vehicles according to experienced drivers" Safety Science, 121, pp. 580-588. https://doi.org/10.1016/j.ssci.2019.02.021

Rolison, J. J., Regev, S., Moutari, S., Feeney, A. (2018) "What are the factors that contribute to road accidents? An assessment of law enforcement views, ordinary drivers' opinions, and road accident records" Accident Analysis \& Prevention 115,pp. 11-24. https://doi.org/10.1016/j.aap.2018.02.025

Sandberg, U. (2012) "Adding noise to quiet electric and hybrid vehicles: An electric issue", Acoustics Australia 10.

Sikdar, P., Rabbani, A., Dhapekar, N.K. (2017) "Hypothesis of data of road accidents in India-review" International Journal of Civil Engineering and Technology, 8, pp. 141146.

Singh, S. K. (2017) "Road Traffic Accidents in India: Issues and Challenges" Transportation Research Procedia, 25, pp. 4708-4719. https://doi.org/10.1016/ j.trpro.2017.05.484

Wall Emerson, R., Naghshineh, K., Hapeman, J., Wiener, W. (2011), "A pilot study of pedestrians with visual impairments detecting traffic gaps and surges containing hybrid vehicles" Transportation Research Part F: Traffic Psychology and Behaviour, 14,pp. 117-127. https://doi.org/10.1016/j.trf.2010.11.007

Weinstein, N. D. (1989) "Effects of personal experience on self-protective behavior" Psychological bulletin, 105, 31.

Wismans, J., Malmek, E. M., Welinder, J., Håland, Y., \& Oldenbo, M. (2011, June). Technology needs for safe electric vehicle solutions in 2030. In Proc. 22nd Int. Technical Conf. on 'Enhanced safety of vehicles', Washington DC, USA (pp. 11-0128).

World Health Organization, issuing body, (2018). "Global status report on road safety".WHO.

World Health Organization. (2016) "Ambient air pollution: A global assessment of exposure and burden of disease",WHO. 
World Health Organization - Foundation for the Automobile and Society, Global Road Safety Partnership, Banque mondiale. (2013) "Pedestrian safety a road safety manual for decision-makers and practitioners". Geneva.

Yang, N., Li, Y., Liu, T., Wang, J., \& Zhao, H. (2020). "Analysis of fatal factors influencing accidents involving two-wheel electric vehicle drivers at intersections" Legal Medicine, 45, 101696.

Open Government Data (OGD) Platform India, (2020) available at https://data.gov.in/ dataset-group-name/road-accidents

\section{Acknowledgements}

We are thankful to Technical Education Quality Improvement Programme (TEQIP) in Veermata Jijabai Technological Institute (VJTI), Mumbai, India for awarding financial assistantship to corresponding author. A sincere thank to all participants and the respondents for their support in the studies.

Conflict of Interest: There is no any conflict of interest in this research. 